\title{
An unusual occurrence of drug induced non-specific interstitial pneumonia and tracheobronchopathia osteochrondroplastica
}

\author{
Jan Bronnert $^{1 *}$, Christopher McAulay ${ }^{2}$ and Matthias Grade ${ }^{3}$ \\ ${ }^{1}$ Department of Pneumology and Infectious Diseases Christliches Krankenhaus Quakenbrück, Quakenbrück, Germany \\ ${ }^{2}$ Department of Radiology, Christliches Krankenhaus Quakenbrück, Quakenbrück, Germany \\ ${ }^{3}$ Department of Gastroenterology and Infectious Diseases, Christliches Krankenhaus Quakenbrück, Quakenbrück, Germany
}

\section{Introduction}

Nitrofurantoin-induced Non-Specific Interstitial Pneumonia (NSIP) [1] is an occasionally diagnosed disease especially in older women. It may arise as an acute or chronic form. Patients typically present with cough and dyspnoe. Complaints of arthralgia, fever, weight loss and fatigue have also been associated.

Tracheobronchopathia Osteochondroplastica (TPO) [2] is a very rare disease of unknown etiology, which can lead to tracheal stenosis through the formation of osseous nodules overlying the cartilaginous rings of the trachea. It was first described by Wilks [3] in 1854 and since then approximately 400 cases have been reported worldwide [4].

\section{Case report}

A 77-year-old woman was admitted to our hospital with a 4-month history of dyspnoea and unproductive cough. She had recently been discharged from another hospital with the diagnosis of lung fibrosis.

On physical examination the patient was slightly distressed with an elevated respiratory rate of 24 breaths / min. Her arterial blood gas taken on air revealed $\mathrm{pO}_{2}$ of $7,506 \mathrm{kPa}$ and $\mathrm{pCO} 2$ of $4,093 \mathrm{kPa}$
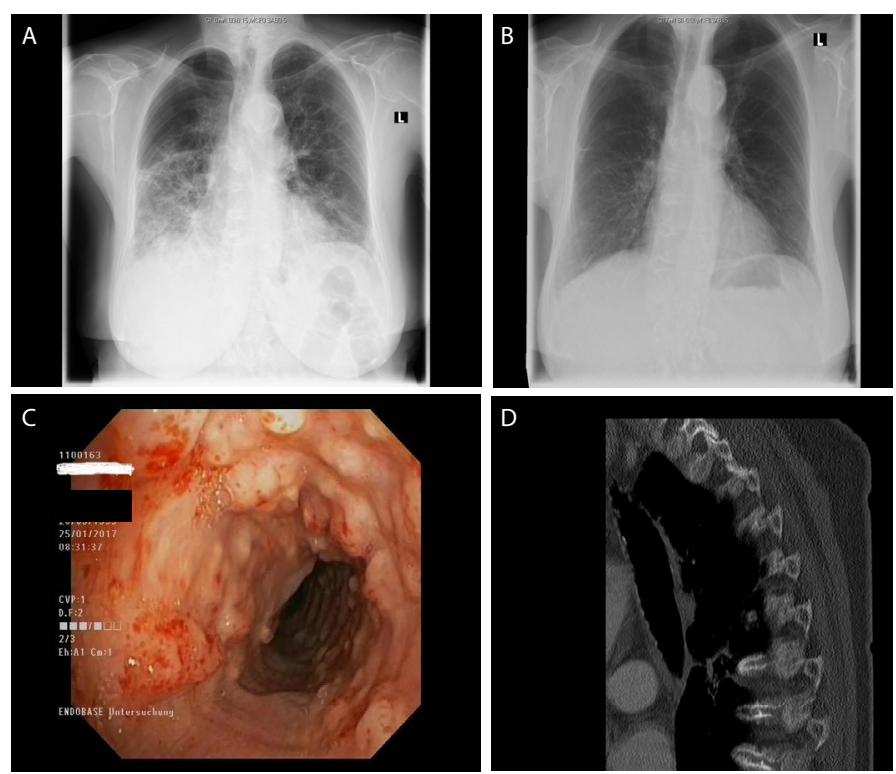

Figure 1. Drug induced Non Specific Interstitial Pneumonia and Tracheobronchopathia Ostochrondroplastica indicating hypoxaemia and hyperventilation.

Subsequent lung function tests reflected a combined obstructive and restrictive ventilation pattern. Chest X-ray demonstrated diffuse bilateral lung infiltration (Figure 1A). The past medical history revealed that the patient had received long term regular nitrofurantoin as prophylaxis for recurrent urinary tract infections. Unexpectedly her bronchoscopy investigation diagnosed a second very rare disease (Figure 1C).

\section{Discussion}

We discontinued the patient's regular nitrofurantoin and commenced a course of prednisolone starting with $60 \mathrm{mg} / \mathrm{d}$, prompting an almost immediate improvement in her clinical symptoms. Two weeks following therapy (prednisolone was reduced to $30 \mathrm{mg}$ ) the infiltration demonstrated on Chest X-Ray had completely resolved (Figure 1B) and the lung function tests had normalised. Steroids may be given for up to 6 months. In addition to a drug induced NSIP we found coincidentally an extensive form of Tracheobronchopathia Osteochrondroplastica, a very rare benign disease of unknown etiology presenting with multiple osseous nodules overlying the cartilaginous rings of the trachea (Figure 1D). The patient suffered no further breathing problems related to the TPO and therefore no intervention was required.

\section{References}

1. Schwaiblmair M, Behr W, Haeckel T, Mark B, Foerg W, et al. (2012) Drug Induced Interstitial Lung Disease. Open Respir Med J 6: 63-74. [Crossref]

2. Zhu Y, Wu N, Huang HD, Dong YC, Sun QY, et al. (2014) A Clinical Study of Tracheobronchopathia Osteochondroplastica: Findings from a Large Chinese Cohort. PLoS One 9: e102068.

3. Wilks S (1857) Ossific deposit on the larynx, trachea and bronchi. Trans Pathol Soc Lond 8: 88 .

4. Junping Sun J, Xie L, Su X, Zhang X (2015) Tracheobronchopathia osteochondroplastica: Case report and literature review. Respir Med Case Rep 15: 14-17. [Crossref]

Copyright: (C2017 Bronnert J. This is an open-access article distributed under the terms of the Creative Commons Attribution License, which permits unrestricted use, distribution, and reproduction in any medium, provided the original author and source are credited.

Correspondence to: Jan Bronnert, Department of Pneumology and Infectious Diseases Christliches Krankenhaus Quakenbrück, Quakenbrück, Germany, Tel: 05431.15-28 42, E-mail: j.bronnert@ckq-gmbh.de

Received: November 22, 2017; Accepted: December 18, 2017; Published: December 22, 2017 